Tropical Journal of Pharmaceutical Research June 2019; 18 (6): 1339-1345

ISSN: 1596-5996 (print); 1596-9827 (electronic)

(1) Pharmacotherapy Group, Faculty of Pharmacy, University of Benin, Benin City, 300001 Nigeria.

\title{
Effect of albumin administration on post-operation mortality, duration on ventilator, and hospital stay on patients in cardiac intensive care: An observational study
}

\author{
Zhen Zhang ${ }^{1 \#}$, Xinlun Dai ${ }^{2 \#}$, Ji Qi ${ }^{1}$, Yu Ao ${ }^{1}$, Chunfeng Yang ${ }^{1}$, Yumei Li ${ }^{1 *}$ \\ ${ }^{1}$ Department of Pediatric Intensive Care Unit, The First Hospital of Jilin University, ${ }^{2}$ Clinical Medical College, Jilin University, \\ Changchun, Jilin 130021, China
}

*For correspondence: Email: yumei5li@yahoo.com; Tel/Fax: 0086-0431-88783975

\begin{abstract}
Purpose: To justify the use of albumin infusion in patients in post-surgery cardiac intensive care unit. Methods: All patients who were hemodynamically stable before the operation and admitted into the surgical intensive care unit following coronary artery bypass, cardiopulmonary bypass, or aortic surgery, had no excessive postoperative bleeding and not on diuretic treatment, were included in the analysis. $A$ total of 1998 patients were divided into two cohorts, viz, the first group was placed on albumin infusion $(n=999)$ while the second group received normal saline infusion $(n=999)$. Data were obtained from DICOM files of patients and records of pharmacy. Wilcoxon test or two-tailed paired t-test followed by Tukey post-hoc tests were performed for statistical analysis at $95 \%$ of confidence level.

Results: Albumin and normal saline administration did not decrease the duration of mechanical ventilation, incidence of mechanical ventilation, need for blood transfusion, and length of hospital stay ( $p$ $>0.05$ ). Albumin infusion decreased the need for fresh frozen plasma transfusion from 85 to 67 , reduced mortality ( $p=0.0005, q=3.959)$, lowered serum lactate level $(p<0.0001, q=43.853)$, but increased cardiac index $(p<0.0001, q=12.192)$ as well as financial burden $(p<0.0001, q=95.158)$ for the patients, compared to normal saline group.

Conclusion: In view of the foregoing, it is recommended that the use of restriction of albumin resuscitation in surgical intensive care unit should be restricted in this subset of patients evluated in this study.
\end{abstract}

Keywords: Artificial respiration, Cardiac surgical procedures, Intensive care unit, Mortality, Infusion, Serum albumin

\begin{abstract}
This is an Open Access article that uses a fund-ing model which does not charge readers or their institutions for access and distributed under the terms of the Creative Commons Attribution License (http://creativecommons.org/licenses/by/4.0) and the Budapest Open Access Initiative (http://www.budapestopenaccessinitiative.org/read), which permit unrestricted use, distribution, and reproduction in any medium, provided the original work is properly credited.

Tropical Journal of Pharmaceutical Research is indexed by Science Citation Index (SciSearch), Scopus, International Pharmaceutical Abstract, Chemical Abstracts, Embase, Index Copernicus, EBSCO, African Index Medicus, JournalSeek, Journal Citation Reports/Science Edition, Directory of Open Access Journals (DOAJ), African Journal Online, Bioline International, Open-J-Gate and Pharmacy Abstracts
\end{abstract}

\section{INTRODUCTION}

Generally, low serum albumin levels commonly occur in patients following cardiac surgery [1] and are associated with poorer outcomes [2]. In such conditions, plasma volume expansion is often necessary [3]. However, there is no clear guideline regarding intravenous infusion for resuscitation [4] but albumin solution is the first choice of the surgeon as plasma expander before or after cardiac surgery in critically ill patients [5]. However, albumin solutions have a 
high cost [6], chances of anaphylactoid reactions, and transmission of allergens, anticoagulants, and microorganisms [7]. In short, use of albumin solutions in critical conditions as resuscitation is controversial [6]. However, several published studies also have such type of controversies in their conclusions as patients with severe sepsis, albumin replacement has not be shown to improve the survival rate [8] another study stated that in patients with severe sepsis, administration of albumin does not alter organs function and have decreased mortality [9]. Both studies are available on high impact factor journals and the results contradict each other. Therefore, there is need for accurate observational study to justify the use of albumin solutions as resuscitation.

The primary aim of the analysis was to evaluate the effectiveness of albumin administration for resuscitation on mortality, freshly frozen plasma transfusions, lactate level, and cardiac index in post-operative patients within the cardiac intensive care unit. The secondary endpoint of the study was to compare incidences and time of mechanical ventilation, requirements of blood transfusion, length of hospital stay, and cost of albumin and normal saline administration in resuscitation in two cohorts.

\section{METHODS}

\section{Ethics statement}

The study was registered in a research registry (www.researchregistry.com), UID No. research registry3953, dated 15 January 2016. The protocol (20160101025JC/OS/19/16, dated 1 January 2016) was approved by First Hospital of Jilin University review board. The study reporting was adhered the law of China, STROBE (the strengthening the reporting of observational studies in epidemiology) guidelines, STROCSS (the strengthening the reporting of cohort studies in surgery) guidelines, and 2013 Declarations of Helsinki [10]. A written informed consent was obtained from all the enrolled patients or their relatives (legally authorized person) by signing a pre-designed patient consent form regarding the interventions, pathology, and publication of work-up in all formats of publication house (hard and/or electronic) irrespective to time and language.

\section{Inclusion criteria}

All patients who had been admitted into the surgical intensive care unit (SICU) in the First Hospital of Jilin University from 16 January 2016 to 1 March 2017 following coronary artery bypass, cardiopulmonary bypass, or aortic surgery procedures were included in the study cohort. Other inclusion criteria were patients who are aged 18 years and above, had normal preoperative serum creatinine and were hemodynamically stable before surgery [11]. The demographic characteristics of the enrolled patients are reported in Table 1. There were no significant differences between the demographic characteristics of patients between groups at the time of analysis $(p>0.01)$.

Table 1: Demographic characteristics of the enrolled patients at the time of analysis

\begin{tabular}{|c|c|c|c|c|}
\hline \multirow{2}{*}{ Patient characteristics } & & \multicolumn{2}{|c|}{ Intravenous infusion } & \multirow{3}{*}{$P$-value } \\
\hline & & \multirow{2}{*}{$\begin{array}{c}\text { Albumin, } N(\%) \\
999\end{array}$} & \multirow{2}{*}{$\begin{array}{c}\text { Normal saline } N(\%) \\
999\end{array}$} & \\
\hline Sample size & & & & \\
\hline \multirow{3}{*}{ Gender } & Male & $390(39)$ & $421(42)$ & \multirow{3}{*}{0.172} \\
\hline & Female & $609(61)$ & $578(58)$ & \\
\hline & $<40$ & $88(9)$ & $98(10)$ & \\
\hline \multirow[t]{2}{*}{ Age (years) } & $40-60$ & 782(78) & $766(77)$ & \multirow[t]{2}{*}{0.85} \\
\hline & $>60$ & 129(13) & 135(13) & \\
\hline \multirow{2}{*}{ Time of resuscitation ${ }^{*}$} & Before surgeries & $323(33)$ & $288(29)$ & \multirow{2}{*}{0.098} \\
\hline & After surgeries & $676(67)$ & $711(71)$ & \\
\hline \multirow{4}{*}{$\begin{array}{l}\text { Numbers of organ(s) } \\
\text { abnormalities }\end{array}$} & 0 & $649(65)$ & 647(65) & \multirow{4}{*}{0.515} \\
\hline & 1 & $247(25)$ & $231(23)$ & \\
\hline & 2 & $103(10)$ & $121(12)$ & \\
\hline & $20-24.9$ & $247(25)$ & $255(26)$ & \\
\hline \multirow[t]{2}{*}{ Serum albumin $(\mathrm{g} / \mathrm{L})$} & $25-29.9$ & $644(64)$ & $626(62)$ & \multirow[t]{2}{*}{0.939} \\
\hline & $>30$ & 108(11) & $118(12)$ & \\
\hline \multirow{4}{*}{$\begin{array}{l}\text { Central venous oxygen } \\
\text { saturation (\%) }\end{array}$} & $80-89$ & $798(80)$ & $783(78)$ & \multirow{4}{*}{0.787} \\
\hline & $90-95$ & $146(15)$ & $151(15)$ & \\
\hline & $>95$ & $55(5)$ & $65(7)$ & \\
\hline & $20-24.9$ & $252(25)$ & $261(26)$ & \\
\hline \multirow[t]{2}{*}{ Body mass index } & $25-29.9$ & $624(63)$ & $607(61)$ & \multirow[t]{2}{*}{0.971} \\
\hline & $>30$ & $123(12)$ & 131(13) & \\
\hline
\end{tabular}




\section{Exclusion criteria}

The patients who had refused to sign an informed consent form and planned any organ transplant with cardiac surgical procedure were excluded from the enrollment. The patients who were admitted into SICU but had not undergone cardiac surgeries were excluded from the study. Patients who were placed on any other kind of crystalloid solutions and/or synthetic colloids resuscitation (other than albumin and normal saline) were also excluded from the analysis. The patients who were first placed on albumin and subsequently given crystalloid solutions and/or synthetic colloids were also excluded from the final analysis. The patients who had discharged against medical advice (DAMA) were also excluded from the analysis. Patients who had excessive postoperative bleeding and on diuretics treatments were excluded from the study.

A total of 1998 patients were included in the two cohorts: First, group of patients were those placed on albumin administration for resuscitation $(n=999)$ and the second, were those placed on normal saline $(n=999)$. STARD (standards for reporting of diagnostic accuracy) flowchart of the analysis is presented in Fig. 1.

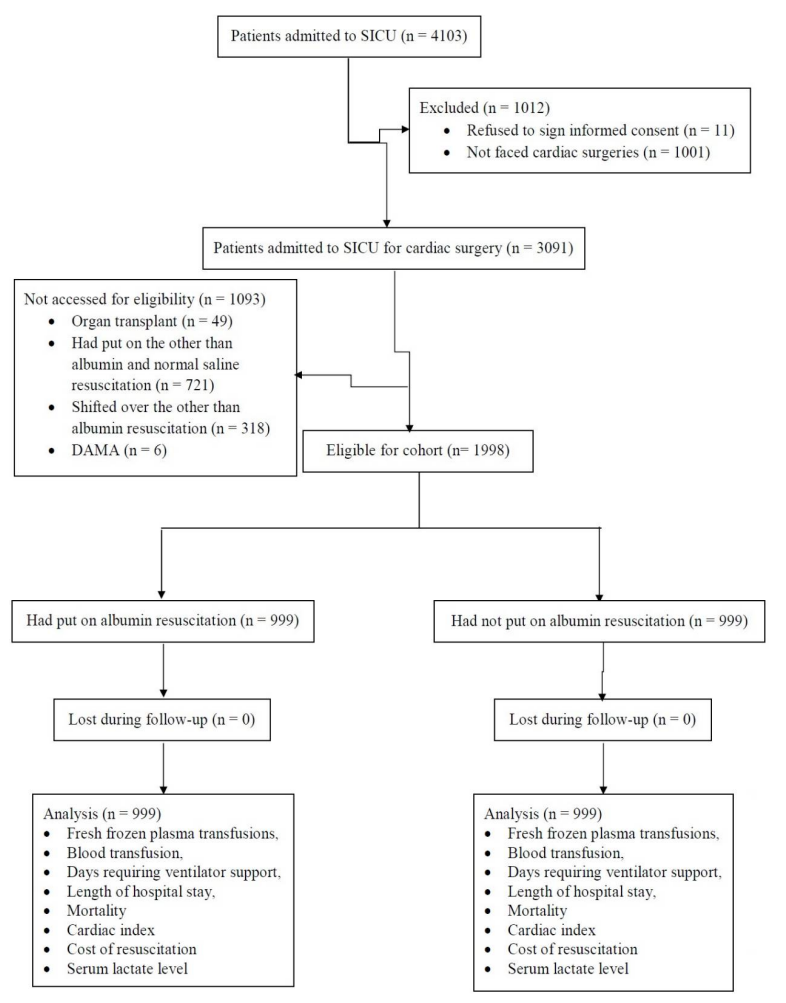

Figure 1: STARD flowchart. Intention-to-treat analysis method. DAMA: Discharged against medical advice, SICU: Surgical intensive care unit

\section{Data collection}

Data regarding the demographic characteristics, number of freshly frozen plasma transfusions, patients requiring blood transfusion, days requiring ventilator support, length of hospital stay, and mortality were obtained from Digital Imaging and Communications in Medicine (DICOM) files of patients preserved in hospital. Albumin utilization and costs were obtained from records of pharmacy.

\section{Statistical analysis}

The Chi-square independent test was performed for the demographic characteristics of patients and constant data of requirements of life support parameters between the groups. Wilcoxon test following Turkey post hoc test (considering critical value $(q)>3.314$ as significant) were performed to compare before and after resuscitation conditions [5]. Two-tailed paired $t$ test [12] following Turkey post hoc test $(q>3.314$ as significant) were performed for the cost of resuscitation, cardiac index, and lactate level between groups. InStat (GraphPad, San Diego, IL, USA) was used for statistical analysis purposes. The demographical characteristics were considered significant at $99 \%$ of confidence level and requirements of life support parameters were considered significant at $95 \%$ of confidence level.

\section{RESULTS}

Albumin and normal saline administration for resuscitation both failed to decrease the length of time on mechanical ventilation, incidences of mechanical ventilation, the requirement for blood transfusion, and length of hospital stay (Table 2).

Albumin resuscitation decreased mortality ( $p=$ $0.0005, q=3.959$ ) however normal saline did not decrease mortality $(p=0.0039, q=3.021)$. The overall survival in both groups was the same $(p=$ 0.928 , Figure 2).

Albumin resuscitation decreased the number of fresh frozen plasma transfusions from 85 to 67 . However, the data was not statistically significant $(p<0.0001, q=2.786)$. Similarly, normal saline resuscitation decreased the number of fresh frozen plasma transfusions from 91 to 87 and the data also was not statistically significant $(p=$ 0.25 , Figure 3 ). 
Table 2: Effect of fluid resuscitation on hemodynamic and blood gas parameters

\begin{tabular}{|c|c|c|c|c|}
\hline \multirow{2}{*}{ Variable } & & \multicolumn{2}{|c|}{ Intravenous infusion } & \multirow[b]{2}{*}{$P$-value } \\
\hline & & $\begin{array}{c}\text { Albumin } \\
999\end{array}$ & $\begin{array}{c}\text { Normal saline } \\
999\end{array}$ & \\
\hline \multirow{4}{*}{$\begin{array}{l}\text { On mechanical } \\
\text { Ventilation }\end{array}$} & Total & $91(9)$ & $97(10)$ & 0.702 \\
\hline & Before resuscitation & $47(5)$ & $49(5)$ & 0.917 \\
\hline & After resuscitation & $44(4)$ & $48(5)$ & 0.749 \\
\hline & $P$-value & 0.25 & $>0.9999$ & $\mathrm{~N} / \mathrm{A}$ \\
\hline \multirow[b]{2}{*}{$\begin{array}{l}\text { Total time of } \\
\text { mechanical } \\
\text { ventilation (days) }\end{array}$} & 0 & $16(2)$ & $12(1)$ & \\
\hline & $\begin{array}{l}1-10 \\
10-19 \\
20-30\end{array}$ & $\begin{array}{c}548(55) \\
347(34) \\
88(9)\end{array}$ & $\begin{array}{c}503(50) \\
399(40) \\
85(9)\end{array}$ & 0.096 \\
\hline \multirow{2}{*}{$\begin{array}{l}\text { Need for blood } \\
\text { transfusion }\end{array}$} & $\begin{array}{l}\text { Before resuscitation } \\
\text { After resuscitation }\end{array}$ & $\begin{array}{l}97(10) \\
87(9)\end{array}$ & $\begin{array}{l}93(9) \\
89(9)\end{array}$ & 0.837 \\
\hline & $\begin{array}{l}P \text {-value } \\
q \text {-value }\end{array}$ & $\begin{array}{c}0.0039 \\
1.34\end{array}$ & $\begin{array}{l}0.25 \\
\mathrm{~N} / \mathrm{A}\end{array}$ & $\begin{array}{l}\text { N/A } \\
\text { N/A }\end{array}$ \\
\hline \multirow[b]{2}{*}{$\begin{array}{l}\text { Total hospital stays } \\
\text { (days) }\end{array}$} & $<50$ & $145(14)$ & $153(15)$ & \\
\hline & $\begin{array}{l}51-99 \\
100-149 \\
>150\end{array}$ & $\begin{array}{l}247(25) \\
455(46) \\
152(15)\end{array}$ & $\begin{array}{l}271(27) \\
447(45) \\
128(13)\end{array}$ & 0.114 \\
\hline \multirow[b]{2}{*}{$\begin{array}{l}\text { Serum lactate level } \\
(\mathrm{mmol} / \mathrm{L})\end{array}$} & Before resuscitation & $1.88 \pm 0.04$ & $1.87 \pm 0.04$ & 0.908 \\
\hline & $\begin{array}{l}\text { After resuscitation } \\
P \text {-value } \\
q \text {-value }\end{array}$ & $\begin{array}{c}1.84 \pm 0.03 \\
<0.0001 \\
43.853\end{array}$ & $\begin{array}{c}1.84 \pm 0.03 \\
<0.0001 \\
43.636\end{array}$ & $\begin{array}{l}0.742 \\
N / A \\
N / A\end{array}$ \\
\hline
\end{tabular}

Nominal data were presented as a number (percentage) and continuous data were represented as mean $\pm S D$. Wilcoxon test following Turkey post hoc test was used for statistical analysis between before and after resuscitation conditions, a $p<0.05$ and $q>3.314$ were considered as significant. The Chi-square independence test was used for statistical analysis between groups, a $p<0.05$ was considered as significant. "Two-tailed paired $t$-test was used for statistical analysis, a $p<0.05$ was considered as significant. N/A: Not applicable. For statistical analysis requirement of life-support was considered as 1 and no requirement of that was considered as 0

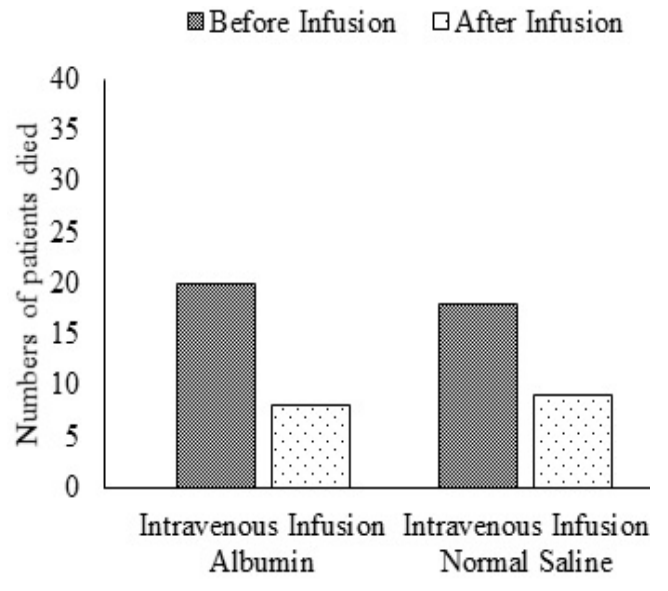

Figure 2: Effect of fluid resuscitation on mortality. The $p$ and $q$ values between before and after resuscitation for albumin and normal saline were 0.0005 and 3.959 and 0.0039 and 3.021 respectively. There was no significant difference in the rate of mortality between albumin and normal saline resuscitation ( $p=0.928)$. Wilcoxon test following Turkey post hoc test was used for statistical analysis between before and after resuscitation conditions, a $p<0.05$ and $q>3.314$ were considered as significant. Chi-square independence test was used for statistical analysis between groups, a $p<0.05$ was considered as significant. For statistical analysis mortality was considered as 1 and survival was considered as 0

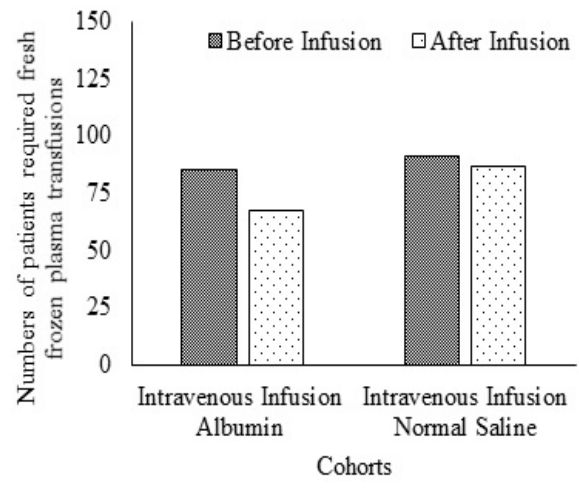

Figure 3: Effect of fluid resuscitation on numbers of fresh frozen plasma transfusions. The $p$ and $q$ values between before and after resuscitation for albumin and normal saline were $<0.0001$ and 2.786 and 0.25 respectively. There was no significant difference for numbers of fresh frozen plasma transfusions between albumin and normal saline resuscitation ( $p=0.447)$. Wilcoxon test following Turkey post hoc test was used for statistical analysis between before and after resuscitation conditions, $p<0.05$ and $q>3.314$ were considered as significant. Chi-square independence test was used for statistical analysis between groups, $p<0.05$ was considered as significant. For statistical analysis requirement of fresh frozen plasma, transfusion was considered as 1 and no requirement of that was considered as 0 
The data derived regarding cost from the pharmacy indicated that the consultant had no clear idea regarding albumin resuscitation. Albumin resuscitation was shown to increase the financial burden to the patients compared to normal saline (341.25 \pm 165.03 \$ vs. $53.72 \pm$ $11.75 \$, p<0.0001, q=95.158)$.

Before resuscitation, there was no significant difference in cardiac index between groups ( $p=$ 0.39). Albumin resuscitation increased the cardiac index of patients after resuscitation of the same patients $(p<0.0001, q=12.192)$. However, normal saline did not improve the cardiac index of patients after resuscitation of the same patients $(p=0.0001, q=1.781)$. In comparison with normal saline, albumin administration successfully improved the cardiac index of patients after resuscitation $(p<0.0001$, $q=11.0$, Figure 4).

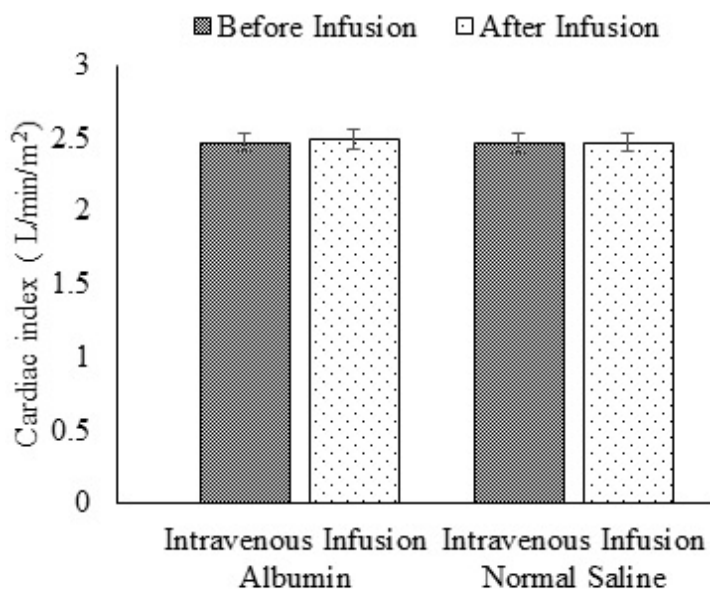

Type of fluid resuscitation

Figure 4: Effect of fluid resuscitation on the cardiac index. The $p$ and $q$ values between before and after resuscitation for albumin and normal saline were < 0.0001 and 12.192 and 0.0001 and 1.781 respectively. Data were represented as mean \pm SD all of them, $n=$ 999.. Wilcoxon test following Turkey post hoc test was used for statistical analysis between before and after resuscitation conditions. Two-tailed paired t-test following Turkey post hoc test was used for statistical analysis. $\mathrm{P}<0.05$ and $\mathrm{q}>3.314$ were considered significant. Cardiac index was found as the ratio of cardiac output to body surface area

\section{DISCUSSION}

The study examined the use of albumin administration for resuscitation in post-operative cardiac patients admitted into the SICU. Hypovolemia after cardiac surgery stimulates an inflammatory response, bleeding, actual volume loss, capillary leak, a high degree of vascular permeability, and vasodilation [5]. There are choices of expensive colloid solutions (albumin or hetastarch) and cost-effective crystalloid fluids (isotonic sodium chloride solution or Ringer lactate) for resuscitation purposes [13]. Crystalloid fluids cause increase in pulmonary edema [14]. Moreover, current guidelines recommended albumin rather than normal saline for resuscitation purposes $[15,16]$. In respect to the choice of resuscitation method adopted in the study, the work has justified the use of albumin.

Unlike normal saline, albumin resuscitation had beneficial effects on short-term physiologic markers, mortality, cardiac index, and numbers of fresh frozen plasma transfusions. These were because albumin has physiological effects as antioxidant, transportation, and binding of hormones and drugs within the blood, regulation of colloid osmotic pressure, buffer capabilities and nitric oxide modulation [17], and improving lung function [9], which are necessary for critically ill patients. However, albumin resuscitation had no beneficial effects on incidences and time of mechanical ventilation, requirements of blood transfusion, and hospital stay. Moreover, poor outcomes are associated with high morbidity [5]. These data had supported the finding of the previous studies $[5,12,18]$. However, paradox results were observed with the other studies [2,9]. In considering effective results of outcomes from the study, it is difficult to conclude that there were sustained clinical benefit of albumin resuscitation in patients in the cardiac intensive care but it however increased the unwanted financial burden on the patient.

In the study, all the enrolled patients in both groups had no overall potential benefits to reduce morbidity. Fluid resuscitation is considered the first line therapy for critically ill patients because it increases intravascular volume and perfusion [19,20] but fluid resuscitation is beneficial only if the patient is on ascending limb of the Frank-Starling curve [21]. Moreover, large fluid resuscitation may also lead to clinical edema [22,23] and this is harmful [24]. In regards to the results from the observational study, the guideline for fluid resuscitation for the single aim of correcting hypovolemia in critically ill patients requires revision to include adequate monitoring and appropriate fluid selection.

Normal saline and albumin resuscitation both succeeded in maintaining serum lactate levels. Lactate is mainly maintained by fluid resuscitation in critically ill patients [25]. However, albumin administration was not superior to normal saline for maintenance of serum lactate level. In respect to biochemical parameters of patients, normal saline and 
albumin administration both had the same effects in fluid resuscitation.

\section{Limitations of the study}

The first limitation was that the study was observational and thus lacked randomization of patients into the two groups. The study did not use the dose oscillation analysis of albumin administration. The observation period at the end of the study was too short. Long-term effects of resuscitation were not evaluated. The study did not report cause of death. The study did not consider the effects of resuscitation on hemoglobin, platelets, and the other blood cells.

\section{CONCLUSION}

The findings of this study show that normal saline administration for resuscitation is safe and feasible in patients under cardiac intensive care, it is surprising why albumin administration for resuscitation is prevalent in clinical practice. The study therefore recommends the restriction of albumin administration for resuscitation and the need for individualized fluid resuscitation therapies in surgical intensive care units.

\section{DECLARATIONS}

\section{Acknowledgement}

Authors are thankful to the medical and nonmedical staff of the First Hospital of Jilin University, Changchun, Jilin, China and Clinical Medical College, Jilin University, Changchun, Jilin, China who supported the study. The study was supported by funds obtained from Natural Science Foundation of Jilin Province, China (Award no. 20160101025JC).

\section{Availability of data and materials}

The datasets used and analyzed during the current study are available from the corresponding author on reasonable request.

\section{Conflict of interest}

No conflict of interest is associated with this work.

\section{Contribution of authors}

We declare that this work was done by the authors named in this article and all liabilities pertaining to claims relating to the content of this article will be borne by the authors. Zhen Zhang and Xinlun Dai contributed equally to this study, amore specifically to the conceptualization of the study and acquisition of data. Ji Qi had contributed to design of the study, analysis, and interpretation of data. Yu Ao had contributed to the conceptualization and funding for the study. Chunfeng Yang had contributed to design of the study and project administrator. Yumei Li had contributed to the analysis of data, drafted, critically revised the manuscript, and given final approval. All authors have agreed to be accountable for all aspects of work ensuring integrity and accuracy. All authors had read and approved the manuscript sent for publication.

\section{Open Access}

This is an Open Access article that uses a funding model which does not charge readers or their institutions for access and distributed under the terms of the Creative Commons Attribution License (http://creativecommons.org/licenses/by/ 4.0) and the Budapest Open Access Initiative (http://www.budapestopenaccessinitiative.org/rea d), which permit unrestricted use, distribution, and reproduction in any medium, provided the original work is properly credited.

\section{REFERENCES}

1. Redelmeier DA. New thinking about postoperative hypoalbuminemia: A hypothesis of occult protein-losing enteropathy. Open Med 2009; 3(4): e215-e219.

2. Bannard-Smith J, Alexander $P$, Glassford $N$, Chan MJ, Lee $M$, Wong BT, Crawford G, Bailey M, Bellomo $R$. Haemodynamic and biochemical responses to fluid bolus therapy with human albumin solution, $4 \%$ versus 20\%, in critically ill adults. Crit Care Resusc 2015; 17(2): 122-128.

3. Skytte LJ, Bragadottir G, Krumbholz V, Redfors B, Sellgren J, Ricksten SE. Effects of acute plasma volume expansion on renal perfusion, filtration, and oxygenation after cardiac surgery: A randomized study on crystalloid vs colloid. Br J Anaesth 2015; 115(5): 736-742.

4. Rozga J, Piatek T, Małkowski P. Human albumin: old, new, and emerging applications. Ann Transplant 2013; 18: 205-217.

5. Rabin J, Meyenburg T, Lowery AV, Rouse M, Gammie JS, Herr D. Restricted albumin utilization is safe and cost-effective in a cardiac surgery intensive care unit. Ann Thorac Surg 2017; 104(1): 42-48.

6. Vincent JL, Russell JA, Jacob M, Martin G, Guidet B, Wernerman J, Ferrer $R$, McCluskey $S A$, Gattinoni $L$. Albumin administration in the acutely ill: what is new and where next? Crit Care 2014; 18 (4). DOI: 10.1186/cc13991.

7. Hammond $N$, Finfer $S$. Fluid resuscitation in the critically ill: what is the next challenge? Rev Bras Ter Intensiva 2015; 27(4): 309-311.

Trop J Pharm Res, June 2019; 18(6): 1344 
8. Caironi P, Tognoni G, Masson S, Fumagalli R, Pesenti A, Romero M, Fanizza C, Caspani L, Faenza S, Grasselli $G$, et al. Albumin replacement in patients with severe sepsis or septic shock. N Engl J Med 2014; 370(15): 1412-1421.

9. SAFE Study Investigators, Finfer S, McEvoy S, Bellomo R, McArthur $C$, Myburgh J, Norton R. Impact of albumin compared to saline on organ function and mortality of patients with severe sepsis. Intensive Care Med 2011; 37(1): 86-96.

10. World Medical Association. World Medical Association Declaration of Helsinki: ethical principles for medical research involving human subjects. JAMA 2013; 310(20): 2191-2194.

11. Legrand M, Mik EG, Balestra GM, Lutter R, Pirracchio R, Payen $D$, Ince $C$. Fluid resuscitation does not improve renal oxygenation during hemorrhagic shock in rats. Anesthesiology 2010; 112(1): 119-127.

12. Fitzgerald $D C$, Holmes $S D$, St Onge JR, loanou $C$, Martin $L M$, Ad N. Systemic inflammatory response during cardiac surgery: a pilot study. Innovations (Phila) 2015; 10(2): 125-132.

13. Perel P, Roberts I, Ker K. Colloids versus crystalloids for fluid resuscitation in critically ill patients. Cochrane Database Syst Rev 2013 (2); CD000567. DOl: 10.1002/14651858.CD000567.pub6.

14. Duchesne JC, Kaplan LJ, Balogh ZJ, Malbrain ML. Role of permissive hypotension, hypertonic resuscitation and the global increased permeability syndrome in patients with severe hemorrhage: adjuncts to damage control resuscitation to prevent intra-abdominal hypertension. Anaesthesiol Intensive Ther 2015; 47(2): 143-155.

15. Bunn $F$ and Trivedi $D$. Colloid solutions for fluid resuscitation. Cochrane Database Syst Rev 2012 (7); CD001319. DOI: 10.1002/14651858.CD001319.pub5.

16. Feldman D, Pamboukian SV, Teuteberg JJ, Birks E, Lietz $K$, Moore SA, Morgan JA, Arabia F, Bauman ME, Buchholz HW, et al. The 2013 International society for heart and lung transplantation guidelines for mechanical circulatory support: executive summary. J Heart Lung Transplant 2013; 32(2): 157-187.
17. Scherzer R, Heymsfield SB, Rimland D, Powderly WG, Tien PC, Bacchetti P, Shlipak MG, Grunfeld C; Study of Fat Redistribution, Metabolic Change in HIV Infection (FRAM). Association of serum albumin and aspartate transaminase with 5-year all-cause mortality in HIV/hepatitis $C$ virus coinfection and HIV monoinfection. AIDS 2017; 31(1): 71-79.

18. Pierce JD, Shen $Q$, Thimmesch $A$. The ongoing controversy: Crystalloids versus colloids. J Infus Nurs 2016; 39(4): 40-44.

19. Tanczos K, Nemeth M, Trasy D, Laszlo I, Palagyi $P$, Szabo Z, Varga G, Kaszaki J. Goal-directed resuscitation aiming cardiac index masks residual hypovolemia: An animal experiment. Biomed Res Int 2015. DOI: $10.1155 / 2015 / 160979$.

20. Konrad FM, Mik EG, Bodmer SI, Ates NB, Willems HF, Klingel K, de Geus HR, Stolker RJ, Johannes T. Acute normovolemic hemodilution in the pig is associated with renal tissue edema, impaired renal microvascular oxygenation, and functional loss. Anesthesiology 2013; 119(2): 256-269.

21. Marik PE, Monnet X, Teboul JL. Hemodynamic parameters to guide fluid therapy. Ann Intensive Care 2011; 1(1). DOI: 10.1186/2110-5820-1-1.

22. Wang $N$, Jiang $L$, Zhu B, Wen Y, Xi XM. Beijing Acute Kidney Injury Trial (BAKIT) Workgroup. Fluid balance and mortality in critically ill patients with acute kidney injury: a multicenter prospective epidemiological study. Crit Care 2015; 19. DOI: 10.1186/s 13054-015-1085-4.

23. Marik PE. latrogenic salt water drowning and the hazards of a high central venous pressure. Ann Intensive Care 2014; 4. DOI: 10.1186/s13613-014-0021-0.

24. Tanczos K, Nemeth M, Molnár Z. The multimodal concept of hemodynamic stabilization. Front Public Health 2014; 2. DOI: 10.3389/fpubh.2014.00034.

25. Dellinger RP, Levy MM, Rhodes A, Annane D, Gerlach $H$, Opal SM, Sevransky JE, Sprung CL, Douglas IS, Jaeschke $R$, et al. Surviving sepsis campaign: International guidelines for management of severe sepsis and septic shock, 2012. Intensive Care Med 2013; 39(2): 165-228. 